\title{
A Functional Account of Grammatical Number in English Reflexive Pronouns
}

\author{
Nancy Stern
}

\begin{abstract}
Number morphology appears twice in English reflexive pronouns, first on the pronominal-possessive portion of the form, and second on the inflectional ending. Usually, the two number markings co-vary, but 'crossed' number forms like ourself and themself - and even myselves and herselves - are also attested. This paper argues that the two opportunities to signal number can be creatively exploited for communicative purposes, and are not controlled syntactically. The data and analysis presented provide support for a view of grammatical categories (even those commonly regarded as syntactically determined) as independent bearers of meaning.
\end{abstract}

Keywords. English; reflexive pronouns; grammatical number; Columbia School; semantics; pragmatics; functional explanation

1. Introduction. Two approaches to syntax have crystallized over the past decades: one view holds that syntax is a formal computational system that is autonomous of meaning, while the other sees grammar as symbolic and meaningful. The former is the position of Chomsky and of generative grammar more generally (Chomsky 1965, 2002, 2012); the latter is the position of cognitive grammar (Langacker 1988) the Columbia School (Diver 1969; Reid 2011; Huffman and Davis 2012), and a variety of other meaning-based approaches occupying what Butler and Gonzalvez-García (2014) call the 'functional-cognitive space.' This paper takes the latter approach to a study of number in English reflexive pronouns. It presents data and an analysis that suggest that grammatical number in these forms is best understood not as a syntactic construct, but rather as a feature of semantic content. That is, the evidence we will review shows that number in reflexive pronouns functions as part of a grammar that is designed to facilitate communication.

As is well known, number morphology appears twice in English reflexive pronouns, first on the pronominal-possessive portion (myself vs ourselves), and second on the inflectional ending of the head (self vs -selves). In most reflexive pronouns, the two number markings covary: the singular pronominal portion co-occurs with singular self (e.g., myself, himself, herself) and the plural pronominal portion co-occurs with plural selves (e.g., ourselves, themselves). ${ }^{1}$ But reflexive pronouns in which the two number meanings do not match (ourself and themselves) have also been noted (Joseph 1979; Quirk et. al. 1985; Wallenberg 2000).

Joseph (1979: 521) proposes that "the selection of the possessive part of reflexive pronouns is a purely syntactically-controlled process, whereas the selection of the singular vs. plural reflexive head (-self/-selves) is a semantically controlled process determined by the number of the antecedent NP." Joseph's analysis differs from the present one in two ways: first, we are proposing that neither selection is based on syntax; secondly, we have found no need to postulate that any sort of "control" (syntactic or semantic), nor any agreement process is operating. Rather, we propose that speakers make choices based on their communicative goals.

\footnotetext{
${ }^{1}$ The pronoun your, which does not indicate number, co-occurs with both self and -selves in yourself and yourselves, and is therefore not part of this study.
} 
Henceforth in this paper, to distinguish the formal syntactic construct from the semantic notion of Number proposed here, we will use an initial capital letter to indicate that we are referring to a notional category rather than a syntactic one. In the sections that follow, we will examine a collection of individual examples to determine on what basis Number morphology in reflexive pronouns was chosen. I hope to demonstrate that speakers and writers are leveraging the available Number meanings in reflexive pronouns in order to advance their communicative goals. To put this another way: the use of Number morphology is these forms is goal-directed, not rule-governed.

2. Data. The analysis presented here aims to explain the distribution of grammatical morphology in terms of the contribution the forms' meanings make to the intended communication. Therefore, data in this study are drawn from naturally occurring discourse, in all its complexity and richness, so that we can observe the contextual factors that contribute to speakers' choices of Number meanings.

Data for this study have been drawn from personal collections, Google searches, and the InfoTrac database. For quantitative comparisons, a search of the Corpus of Contemporary American English or COCA (Davies 2008) revealed the attested pronouns shown in Table 1, with their frequencies.

\begin{tabular}{lr} 
Form & Frequency \\
\hline myself & 78,881 \\
myselves & 3 \\
yourself & 54,926 \\
yourselves & 2,015 \\
himself & 140,087 \\
himselves & 6 \\
herself & 70,509 \\
herselves & 1 \\
itself & 89,425 \\
itselves & 0 \\
ourself & 162 \\
ourselves & 25,308 \\
themselves & 107,610 \\
themself & 108
\end{tabular}

Table 1. Attested self pronouns in COCA (Davis 2008)

More tokens of all these forms can be discovered via internet searches (including itselves, which does not appear in COCA). While the numbers are low for mismatched Number meanings, we will show that their occurrence is neither random nor due to performance errors; rather, the communicative circumstances of these examples show that speakers have chosen non-matching Number meanings to meet their communicative goals. We begin with ourself and themself, the most frequently occurring forms in which two different Number meanings are signaled, and then we will turn to other, more surprising examples.

2.1 OURSELF. While the form ourselves is used far more commonly than ourself, speakers appear to use ourself in productive ways. In (1), plural our and singular self each reflect a different notional aspect of the message, and appears to serve the speaker's intended 
communication quite well. In the example, a manager is lamenting his team's recent performance:

(1) [If we continue to play poorly], "we'll be throwing dirt on our own grave," Rockies manager Don Baylor says. "We won't need anyone to shovel for us. We'll be shoveling for ourself." (NSN)

The speaker unsurprisingly refers to the players and coaches with the plural pronouns we (along with plural pronouns our and $u s$ ), to refer to the actions of all the players; he wouldn't want to use a first-person singular pronoun and say I'll be throwing dirt or I'll be shoveling. But in the self pronoun, the speaker is not limited to a binary choice between singular and plural. In ourself, the plural meaning of our refers to all the people on the team who will be shoveling. The singular meaning of self refers to the team as a whole. After all, there will be just one grave for the whole group. The combination of plural our with singular self is communicatively quite effective because it captures both the plurality of team members, and the notion that the team is a single unit.

The next example of ourself is drawn from an academic journal in an article about the ownership of the name Cellular and Molecular Biology.

(2) In the wake of an ugly battle that has erupted between Pergamon Press Ltd. and the editor of one of its journals, there are now two versions of Cellular and Molecular Biology.... Both parties insist that their journal is the legitimate one and the other is an imposter, and lawsuits are in the works... "We own that title," he [the publishing director of Pergamon Press] says. Nevertheless, he explains, "pending the resolution of the issue we need to find a mechanism to distance ourself from this product." (SCA)

The speaker is using the first person pronoun we, to refer to a publishing company that consists of many individuals and journals. Nevertheless, the company is a single organization, one that does not want to be misidentified with what it considers an inferior journal. Each Number choice is made in response to a different facet of the message, which serves the speaker's communicative needs well, as he is referring both to a group of individuals and to a single organization. The plural meaning of our refers to the multiple elements that form the company, while singular self refers to the company as a whole that must be protected in the dispute.

Let us consider two additional instances of ourself before we turn to examples of other pronouns. In (3), a motivational speaker is describing the characteristics of one of her employees. The passage describes an idea about people in general, that we are all responsible for our own destinies:

(3) Sue believes in Sue. She is committed to the idea that we are all masters of ourself.

She knows in her gut that it's not what happens to us but how we handle it. (NVS)

When the speaker says "we are all" and "what happens to us," and "how we handle it," she's including herself, along with her audience, to describe who this observation applies to; it applies to all of us. But there is a distributive interpretation in "we are all masters of ourself." The author is not saying that we are all responsible for the destiny of a group. The our tells us she is referring to many people, and the singular self form says that each person in the group is responsible for the destiny of one person.

Finally, ourself performs a similar function in (4): 
(4) There are times, too, when we hate the man we love because he reflects a different image of ourself than the one we would like other people to see. (GCW)

Here again, we have a distributive interpretation in which plural our is telling us about a general condition of humankind, while singular self is referring to each person's individual experience. There is additional, corroborating evidence for this interpretation in the text: the plural meaning is also found in the word "we," which occurs twice, and the fact that the passage is about an individual experience is shown by the singular "the man we love," and "a different image".

2.2 THEMSELF. Another widely attested reflexive pronoun which carries two different Number meanings is themself. In the more frequently occurring themselves, the plural ending is an unremarkable case in which the Number meaning of -selves is the same as the Number meaning of them. However, the two opportunities to signal Number offer speakers expressive opportunities that are not available in them and they alone.

It has been widely noted (Newman 1992, 1997; Lagunoff 1997) that the pronoun they is often used for singular referents when the identity of that referent is unknown or not specific, as in (5), in which both they and their refer to a single person:

(5) If a student has a question, they should raise their hand.

Example (6) is an illustrative example of the use of themself to refer to a single, unnamed and not specific individual:

(6) Before you create an intervention when an autistic student talks to themself, you need to ask yourself why they are doing it. (TTW)

Although the writer is describing a general phenomenon that applies to a group of people (autistic students), it is phrased in terms of a single person: an autistic student. So while plural they appears to be a communicatively useful strategy for referring to non-specific individuals (cf. above), the Number meaning of -self need not simply mirror the plural meaning of them. As the speaker is actually referring to just one individual at a time, the singular meaning of -self fits the intended communication quite well.

In spite of the communicative utility of themself to refer to non-specific individuals (as in (6), we also find the frequently attested form themselves in such contexts, as in (7). There are a variety of reasons for the use of themselves in such contexts. Many theorists hold that language is a tool used by human beings, and that as such, the general cognitive and behavioral traits of people come into play in its use (Diver 2012, Langacker 1987, Lakoff 1990). Because language is a social behavior, it is subject to normative pressures, and these also influence speakers' choices of forms (Cameron 2005). Proscriptions against the use of themself are common (Whitley 1978, Soanes 2013), and many speakers surely avoid it on those grounds. So prescriptive pressures and doing things the way they are usually done may lead some speakers to choose themselves even when themself would be more felicitous:

(7) For a certain kind of woman it is essential that they be fully developed themselves before they can marry. (JGC)

In the next example, there is some evidence that the speaker (a professor) does not feel constrained by prescriptive pressures, since he avoids the prescriptively favored whom in "keep track of who nominates who:

(8) I am chair of the committee that has to decide the best paper in language testing .... 
I have been asked to state publicly whether self-nominations are accepted. To the best of my knowledge, there is no reason why a person should not nominate

themself. As chair, I would not hesitate to accept a self nomination. A paper is nominated, that's all; who nominates it is not relevant, and I make no effort to keep track of who nominates who. (RBK)

This writer has chosen them to refer to people whose identities are unspecified (anyone who might self-nominate for the award). However, because he was referring to just one selfnominator, he had no reason to re-select the plural meaning with selves, and instead paired them with singular self.

2.3. Other REFLEXIVE PRONOUNS. As shown in Table 1, it is not only in ourself and themself that we see speakers creatively manipulating the available meanings of linguistic forms to meet their communicative goals. There are also attested instances of myselves, herselves, and even himselves. Not surprisingly, such examples have rather specific contexts, because the messages communicated in these cases are generally rather unusual.

In (9), there is one speaker with two different identities: his usual persona and his drag queen identity:

(9) [A man discussing his identity as a drag queen, Lola Berry] I felt incapable of living up to Lola Berry. I was now in a bizarre competition with myselves. (SBH)

In this example, $m y$, with its singular meaning, corresponds to the speaker being one person; the plural meaning of selves corresponds to his multiple identities.

Similarly in (10), there is another individual with multiple identities:

(10) [A man who describes himself as schizoid says] After my release, I multiplied myselves like the police, and grew as crooked, if not quite as preachy. (TDC)

Here too, uncommon communicative circumstances led speakers to choose multiple meanings, motivated each by a different aspect of the message. In this example, the speaker wants to identify himself as both one individual (my) and as a plurality of identities (selves), corresponding to a disordered emotional state in which he has multiple personalities.

The next example of her plus selves pertains to Shirley MacLaine, an actress known for her belief in reincarnation and past lives:

(11) Though she did not want to be pinned down about the when's and where's, she said, she has not spent one dime of seminar earnings on any of herselves (either past or present). (HSB)

Again, the singular meaning of her corresponds to the single individual named Shirley MacLaine, while the plural meaning of selves refers to her multiple past lives. As we have seen before, each Number choice reflects the counting of different things.

Example (12) is another instance of her plus selves, from a review of a children's book in which the main character travels in time:

(12) This is the third book in a series. It is fun and has some neat ideas such as when Molly (age 11) suddenly meets herself at several different ages, infant, 2, 6, and 10 and experiences all of the memories of all of herselves at the same time. (MMH)

In this passage, we have both herself and herselves, which tells us that the writer is making a distinction between the her + selves as two separate words, and as a single pronoun. In both 
cases, Molly is just one person, signaled by the pronoun her. In the first instance (herself), the writer describes Molly at one point in time meeting herself at different ages - her age varies, but her singular identity remains constant, and this is indicated with singular self. But, in the second case, with herselves, the writer is saying that Molly experiences the memories of these multiple selves "at the same time". The singular meaning of her refers to Molly the person, and the plural meaning of selves refers to Molly's multiple identities through time.

The last example is from an academic symposium held by the Poetics and Linguistics Association, in which one of the speakers entitled his paper:

\section{(13) Conversation Among Himselves: Change and the Style of Henry James ( $\mathrm{HCH})$}

The presenter described three different stages of James's work, and the connections among them: he chose singular him for the one person, Henry James, or perhaps for the singular body of his writings; and plural selves, for those different stages of James's work that are in conversation with each other. As in the other examples we have seen, this speaker took advantage of the opportunities to signal Number twice in the reflexive pronoun, to describe the ideas he wants to express.

One might wonder whether the occurrences of myself and herself are not instances of reflexive pronouns, but instead, are actually two words, my + self and her + self. For purposes of this analysis that is not an important distinction, because in either case, speakers are choosing the Number meanings that will communicate their intended messages. Also, the occurrence of the form himselves shows that it is not impossible that these are indeed individual pronouns, as himselves could not be produced by combining a separate possessive pronoun (his) with self.

3. A theoretical framework. The data supports the position that speakers are choosing grammatical morphology on the basis of the contribution that the forms make to communication. These findings are consistent with previous work carried out within the Columbia School framework, a resolutely functionalist approach in which meanings are posited not only for lexical items, but for all grammatical morphology as well (Huffman and Davis 2012; Reid 2011; Diver 1969).

Columbia School linguistics is based on a fundamental idea that is controversial for linguists, but which non-linguists always find trivial: language is essentially a device of communication (Diver 1995 [2012]). In this view, linguistic structure is essentially semantic; speakers (and writers) choose not only lexical items but also grammatical morphology that helps communicate the messages they wish to express.

As noted earlier, the term Number has been used in this paper to refer to semantic notions, not to syntactic categories. In fact, even the term 'semantic' will require some explication. Semantics is understood here not in terms of truth-values of sentences. Rather, the communicative import of an utterance is understood to be far richer and more complex than would be accounted for by truth conditions.

In the Columbia School approach, analysts aim to account for the distribution of forms, and an important distinction is made between meaning and messages (Contini-Morava 1995, Diver 1995 [2012], Huffman 2001, Otheguy 2002, Reid 1991). In this framework, meaning is understood as the semantic values that are linguistically encoded by lexical and grammatical signs. Messages, on the other hand, are understood to be the interpreted results of communications. The distribution of forms is explained by the contributions that meanings make to messages in actual communicative situations. 
Within Columbia School work, Number has been postulated as a semantic substance (cf. Reid 1991, 2011). While we have used the terms singular and plural in this paper, it will be more accurate to refer to the semantic concepts directly in terms of the meanings they communicate: ONE and MORE THAN ONE. ${ }^{2}$ In addition, Columbia School analysts do not postulate universal constructs in advance of analysis. We have found no reason to posit agreement as an explanatory construct in accounting for grammatical number morphology in English -self pronouns, and we would do so only if the construct were found to be the best solution to the distributional problem.

In Columbia School terms, each occurrence of the pronominal portion of a reflexive pronoun signals a meaning of Person; some of the forms signal Sex (him, her, and its), and all signal a Number meaning of either ONE or MORE THAN ONE (except in the case of your, where Number meaning is unspecified). Likewise, the $-s$ ending of selves signals the meaning MORE THAN ONE, and the lack of that ending on -self signals a meaning of ONE. These meanings are schematized in Figure 1.

\begin{tabular}{|l|c|c|c|}
\hline & Person & Sex & Number \\
\hline my - & SPEAKER & & ONE \\
\hline your- & HEARER & & \\
\hline him- & OTHER & MALE & ONE \\
\hline her - & OTHER & FEMALE & ONE \\
\hline it - & OTHER & NEUTER & ONE \\
\hline our - & SPEAKER & & MORE THAN ONE \\
\hline them- & OTHER & & MORE THAN ONE \\
\hline
\end{tabular}

Plus:

\begin{tabular}{|c|c|}
\hline & Number \\
\hline$($ Self +$)-0$ & ONE \\
\hline Self +$)-s$ & MORE THAN ONE \\
\hline
\end{tabular}

Figure 1. Meanings signaled by -self pronouns

By hypothesis, these meanings are signaled every time the forms are used. Naturally, in most communicative situations, speakers will repeat the same Number meanings within the same pronoun. But, for complex communications, where there are multiple elements to count with respect to the same referent, speakers can make use of the opportunity to signal meaning twice by choosing different meanings within the pronoun.

4. Conclusion. The data we have surveyed constitute evidence that the two Number meanings in English self pronouns represent independent expressive choices. Like other Columbia School work, this analysis has aimed to offer an explanatory account of a range of observable phenomena. We have considered instances of crossed Number pairings in self pronouns, and have tried to explain them not as anomalies, but rather, as productive uses of the communicative resources that are available as part of the linguistic system.

\footnotetext{
${ }^{2}$ Columbia School linguists also avoid positing grammatical categories unless they have been shown to be analytically useful. Convenient labels derived from traditional grammar (such as singular and plural) are therefore eschewed. In Columbia School work, the term -self pronoun has been found to be preferable to "English reflexive pronoun" (Stern 2004, 2006).
} 
It is important to note that Number in -self pronouns has not been analyzed in terms of agreement, or even of agreement failures (cf. Reid 2011). Rather, this analysis simply has no reason to introduce the notion of agreement as a theoretical construct to account for the distribution of Number morphology in English -self pronouns.

We have seen that speakers are making choices of grammatical categories (the meanings ONE and MORE THAN ONE) on the basis of their expressive intent. It would be a grave mistake to dismiss the examples we have reviewed as nothing more than performance errors, or as poetic uses of language. If we set them aside, we lose the very data that show the true flexibility of the linguistic system, and most strikingly reveal how language works.

\section{Data Sources}

HCH: D. L. Hoover, 2006 Poetics and Linguistics Association International Symposium, Lancaster University.

HSB: The History of the Bathing Suit, television documentary, The Learning Channel

TTW: Teacher Tips: What Is Self Talk and Why It Affects Your Student with Autism. http://www.brighthubeducation.com/special-ed-neurological-disorders/94866-interventionwhen-a-student-with-autism-talks-to-himself/ [Note: this website was updated since the data was collected in 2010; as of April 27, 2016, themself was changed to him- or her-self]

JGC: Joan Ganz Cooney, Vanity Fair, June 1994, p. 80. Quoted in Lagunoff (1997), pp. 25 and 188.

MMH:vhttp://www.goodreads.com/book/show/799076.Molly_Moons_Hypnotic_Holiday (Accessed October 2, 2010)

SBH: Robert Serian. Big Hair and New Makeup. Drag and Gay Identity, Whole Earth Review, Fall 1987, p. 2 (6).

TDC: Rei Terada. Dino Campana, Poetry, June 1996 (v 168 n 3 p 137 (1)).

\section{References}

Butler, Christopher \& Francisco Gonzálvez-García. 2014. Exploring functional-cognitive space. Amsterdam and Philadelphia: Benjamins. http://dx.doi.org/10.1075/slcs.157

Cameron, Deborah. 2005. Verbal hygiene. London and New York: Routledge.

Chicago Manual of Style, $16^{\text {th }}$ ed.: The essential guide for writers, editors, and publishers. Chicago: University of Chicago Press.

Chomsky, Noam. 1965. Aspects of the theory of syntax. Cambridge, MA: MIT Press.

Chomsky, Noam. 2002. On nature and language, ed. by Adriana Belletti and Luigi Rizzi. Cambridge University Press.

Chomsky, Noam. 2012. The science of language: Interviews with James McGilvray. Cambridge University Press.

Contini-Morava, Ellen, and Barbara Sussman Goldberg, eds. 1995. Meaning as Explanation: Advances in linguistic sign theory. Berlin/New York: Mouton de Gruyter.

Davies, Mark. (2008-) The Corpus of Contemporary American English: 520 million words, 1990-present. Available online at http://corpus.byu.edu/coca/.

Diver, William. 2012. The nature of linguistic meaning. In Alan Huffman and Joseph Davis, Language: Communication and human behavior: The linguistic essays of William Diver, 47-63. Leiden/Boston: Brill. 
Diver, William. 1995 [2012]. Theory. In Alan Huffman and Joseph Davis, Language: Communication and human behavior: The linguistic essays of William Diver, 445-519. Leiden/Boston: Brill. http://dx.doi.org/10.1163/ej.9789004208582.i-566.

Diver, William. 1969. The system of relevance of the Homeric verb. Acta Linguistica Hafniensia 12(1): 45-68. http://dx.doi.org/10.1080/03740463.1969.10415425.

Huffman, Alan. 2001. The linguistics of William Diver and the Columbia School. WORD 52(1): 29-68. http://dx.doi.org/10.1080/00437956.2001.11432507.

Joseph, Brian. 1979. On the Agreement of Reflexive Forms in English. Linguistics 17: 519523.

Lagunoff, Rachel. 1997. Singular They. Ph.D. dissertation, UCLA.

Lakoff, George. 1990. The Invariance Hypothesis: Is abstract reason based on image-schemas? Cognitive Linguistics 1(1): 39-74. http://dx.doi/org/10.1515/cogl.1990.1.1.39

Langacker, Ronald. 1987. Foundations of Cognitive Grammar: Volume I, Theoretical Prerequisites. Stanford, CA: Stanford University Press.

Langacker, Ronald. 1988. An overview of cognitive grammar. In Brygida Rudzka-Ostyn (ed.), Topics in cognitive linguistics. Amsterdam and Philadelphia: Benjamins.

Newman, Michael. 1992. Pronominal disagreements: The stubborn problem of singular epicene antecedents. Language in Society, 21, pp 447-475. http://dx.doi/org/10.1017/S0047404500015529.

Newman, Michael. 1997. Epicene Pronouns: The Linguistics of a Prescriptive Problem. New York: Garland.

Otheguy, Ricardo. 2002. Saussurean anti-nomenclaturism in grammatical analysis: A comparative theoretical perspective. In Wallis Reid, Ricardo Otheguy, and Nancy Stern (eds.), Signal, meaning and message, 373-403. Amsterdam and Philadelphia: Benjamins. http://dx.doi/org/10.1075/sfsl.48

Quirk, Randolph, Sidney Greenbaum, Geoffrey Leech, and Jan Svartvik. 1985. A Comprehensive Grammar of the English Language. London: Longman.

Reid, W. 2011. The communicative function of English verb number. Natural Language \& Linguistic Theory, 29(4), 1087-1146. http://dx.doi/org 10.1007/s11049-011-9154-0. Reid,

Wallis. 1991. Verb and Noun Number in English: A functional explanation. London and New York: Longman.

Soanes, Catherine. 2013. Is themself a real word? Oxfordwords Blog. http://blog.oxforddictionaries.com/2013/01/themself/

Stern, Nancy. 2006. Tell Me About Yourself: A unified account of -self pronouns. In Joseph Davis, Radmila J. Gorup, and Nancy Stern (eds.), Advances in Functional Linguistics: Columbia School beyond its origins, 177-194. Amsterdam and Philadelphia: Benjamins, http://dx.doi/org/10.1075/sfs1.57.

Stern, Nancy. 2004. The Semantic Unity of Reflexive, Emphatic, and Other -Self Pronouns. American Speech, 79 (3): 270-280. http://dx.doi/org/10.1215/00031283-79-3-270

Wallenberg, Joel Constantine. 2005. A Story of the American -self: a case study in morphological variation. Penn Working Papers in Linguistics, Vol 11: Proceedings of the $28^{\text {th }}$ Annual Penn Linguistics Colloquium.

Whitley, M. Stanley. 1978. Person and number in the use of we, you and they. American Speech, 5, 18-39. http://www.jstor.org/stable/455337 